\title{
Cyclic nucleotide phosphodiesterase 3A-deficient mice as a model of female infertility
}

\author{
Silvia Masciarelli, ${ }^{1}$ Kathleen Horner, ${ }^{2}$ Chengyu Liu, ${ }^{3}$ Sun Hee Park, ${ }^{1}$ Mary Hinckley, ${ }^{2}$ \\ Steven Hockman, ${ }^{1}$ Taku Nedachi, 2 Catherine Jin,2 Marco Conti,2 and Vincent Manganiello' \\ 1 Pulmonary-Critical Care Medicine Branch, National Heart, Lung, and Blood Institute (NHLBI), NIH, Bethesda, Maryland, USA. \\ 2Division of Reproductive Biology, Department of Obstetrics and Gynecology, Stanford University School of Medicine, Stanford, California, USA. \\ ${ }^{3}$ Laboratory Research Program, NHLBI, NIH, Bethesda, Maryland, USA.
}

\begin{abstract}
Since cAMP blocks meiotic maturation of mammalian and amphibian oocytes in vitro and cyclic nucleotide phosphodiesterase 3A (PDE3A) is primarily responsible for oocyte cAMP hydrolysis, we generated PDE3A-deficient mice by homologous recombination. The $P d e 3 a^{-/-}$females were viable and ovulated a normal number of oocytes but were completely infertile, because ovulated oocytes were arrested at the germinal vesicle stage and, therefore, could not be fertilized. $P d e 3 a^{-/}$oocytes lacked cAMP-specific PDE activity, contained increased cAMP levels, and failed to undergo spontaneous maturation in vitro (up to 48 hours). Meiotic maturation in Pde3 $\mathrm{a}^{-/}$oocytes was restored by inhibiting protein kinase A (PKA) with adenosine-3', $5^{\prime}$-cyclic monophosphorothioate, Rp-isomer (Rp-cAMPS) or by injection of protein kinase inhibitor peptide (PKI) or mRNA coding for phosphatase CDC25, which confirms that increased cAMP-PKA signaling is responsible for the meiotic blockade. Pde $3 \mathrm{a}^{-/}$oocytes that underwent germinal vesicle breakdown showed activation of MPF and MAPK, completed the first meiotic division extruding a polar body, and became competent for fertilization by spermatozoa. We believe that these findings provide the first genetic evidence indicating that resumption of meiosis in vivo and in vitro requires PDE3A activity. $P \mathrm{de}^{-1 /-}$ mice represent an in vivo model where meiotic maturation and ovulation are dissociated, which underscores inhibition of oocyte maturation as a potential strategy for contraception.
\end{abstract}

\section{Introduction}

Although competent to complete meiosis, mammalian oocytes are physiologically arrested in prophase I (prophase of the first meiotic division) until shortly before ovulation. Through protein kinase Acatalyzed (PKA-catalyzed) phosphorylation of unidentified proteins, cAMP prevents activation of maturation-promoting factor (MPF) and MAPK signaling in oocytes and inhibits the spontaneous maturation that occurs in vitro, thus maintaining meiotic arrest (1-5). It is unclear, however, whether the same mechanisms of meiotic arrest operate in vivo during each reproductive cycle, where preovulatory gonadotrophin triggers resumption of meiosis and progression through the second meiotic division until metaphase II. Only oocytes arrested in metaphase II can be fertilized.

Cyclic AMP apparently plays an important role in maintaining meiotic arrest in mammalian oocytes. The interplay of signals arising in both follicle cells and oocytes themselves $(1,2,4,6,7)$ regulates synthesis and degradation of oocyte cAMP via adenylyl cyclases and cyclic nucleotide phosphodiesterases (PDEs), respectively. Cyclic AMP may enter oocytes from adjacent cumulus cells via gap junctions $(2,6)$. Recent studies in rodents, however, demonstrated that active oocyte adenylyl cyclase contributes to meiotic blockade (8), which can be released by microinjection of oocytes

Nonstandard abbreviations used: adenosine- $3^{\prime}, 5^{\prime}$-cyclic monophosphorothioate, Rp-isomer (Rp-cAMPS); A-kinase anchoring protein (AKAP); cyclic nucleotide phosphodiesterase (PDE); follicle-stimulating hormone (FSH); germinal vesicle breakdown (GVBD); glucagon-like peptide-1 (GLP1); human chorionic gonadotropin (hCG); luteinizing hormone (LH); maturation promoting factor (MPF); mouse Pde3a (MPde3a); neomycin phosphotransferase II (NPTII); polar body (PB); pregnant mare serum gonadotropin (PMSG); protein kinase A (PKA); protein kinase inhibitor peptide (PKI)

Conflict of interest: The authors have declared that no conflict of interest exists.

Citation for this article: J. Clin. Invest. 114:196-205 (2004)

doi:10.1172/JCI200421804 with antibodies that inactivate Gs, the heterotrimeric GTP-binding protein that activates adenylyl cyclase (9). These studies imply that generation of intra-oocyte cAMP is sufficient to maintain meiotic arrest. In Xenopus oocytes, meiotic arrest involves PKAinduced phosphorylation of protein phosphatase CDC25 (10), and in oocytes from sterile female $C d c 25 b^{-/-}$mice, which are arrested in prophase I, microinjection of CDC25B reinitiated meiosis (11), suggesting that phosphorylation/dephosphorylation of critical effectors is important in oocyte maturation $(1,3,5,10,11)$.

PDEs belong to a complex and diverse superfamily of at least 11 structurally related, highly regulated, and functionally distinct gene families (PDE1-PDE11), which differ in their primary structures, affinities for cAMP and cGMP, responses to specific effectors, sensitivities to specific inhibitors, and regulatory mechanisms (12). Most PDE families comprise more than one gene, which generate multiple protein products via alternative mRNA splicing or utilization of different promoters and/or transcription initiation sites. The two PDE3 subfamilies, PDE3A and PDE3B, are encoded by closely related genes (13). PDE3A is relatively highly expressed in oocytes, platelets, and cardiac, vascular, and airway myocytes; PDE3B, in adipose tissue, liver, and pancreas, as well as cardiovascular tissues (13-16). PDE3 inhibitors increase myocardial contractility, inhibit platelet aggregation, and enhance vascular and airway smooth muscle relaxation $(12,13)$. Activation of PDE3B is thought to be important in the antilipolytic and antiglycogenolytic actions of insulin, as well as in IGF1- and leptin-induced inhibition of cAMP-stimulated secretion of insulin from pancreatic islets (16-19). Other studies suggest that, in pancreatic islets, $\mathrm{PDE} 3 \mathrm{~B}$ regulates intracellular cAMP pools that modulate glucose- and glucagon-like peptide-1-stimulated (GLP1-stimulated) insulin release $(20,21)$.

Oocyte cAMP hydrolysis is thought to be primarily accomplished by PDE3A $(22,23)$, and selective PDE3 (not PDE4 or PDE5) inhibi- 
A

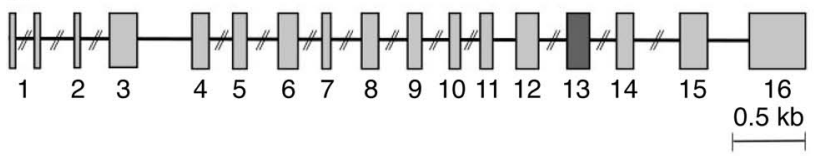

B

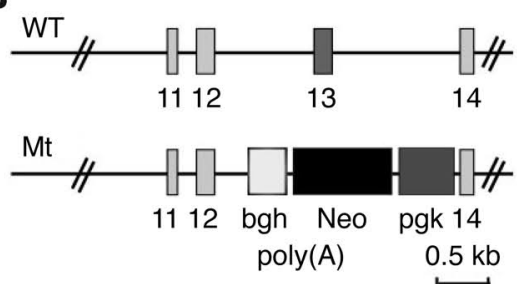

C

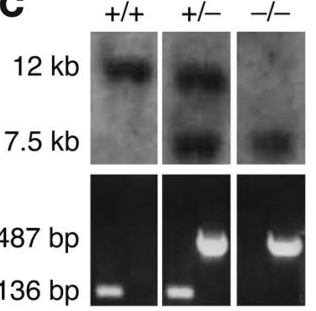

D

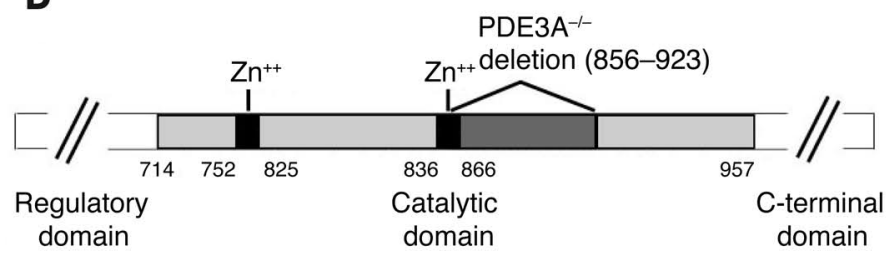

E

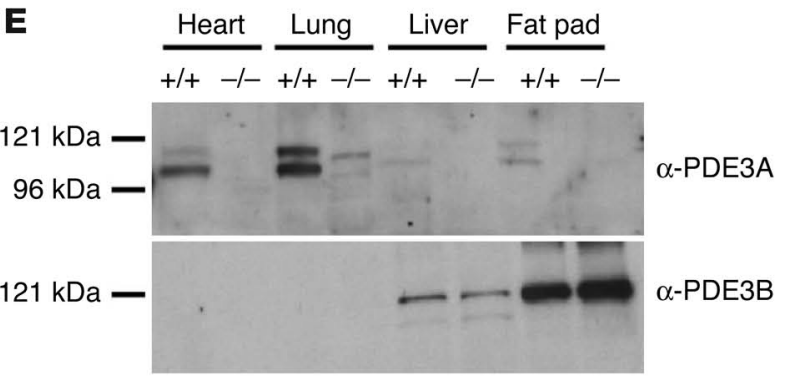

\section{Figure 1}

Gene and protein structures in Pde3a $\mathrm{a}^{+/+}$and $\mathrm{Pde} 3 \mathrm{a}^{-/-}$mice. (A) Putative gene structure of mouse Pde3a (NCBI accession number NT_039360). Double slash marks (//) indicate that introns are not drawn to scale. (B) From an approximately 7-kb genomic (129/SvJ) fragment that included $\mathrm{MPde} 3 \mathrm{a}$ exons 11-14, a targeting vector was constructed that consisted of an approximately $2.5-\mathrm{kb}$ fragment containing MPde3A exons 11 and 12, the NPTII coding sequence (Neo), an approximately 3.5-kb fragment containing MPde3a exon 14, and the TK coding sequence. By homologous recombination in 129/SvJ ES cells, MPde3a exon 13 (WT) was replaced by Neo cassette (mt). (C) Southern blots (using a probe directed upstream from the $5^{\prime}$ end of the genomic fragment used to construct the targeting vector) and PCR analysis of genomic DNA isolated from tails of $P d e 3 a^{+/+}, P d e 3 a^{+/-}$, or $P d e 3 a^{-/-}$mice. Top row: BamH1 restriction fragments of approximately $12 \mathrm{~kb}$ and $7.5 \mathrm{~kb}$ from $P d e 3 a^{+/+}$and $P d e 3 a^{-/}$mice, respectively. Bottom row: PCR amplification of part of exon 13 ( $\left.136 \mathrm{bp}\right)$ of the normal (+) allele; and of part of Neo sequence ( $487 \mathrm{bp}$ ) of the mutant (-) allele. (D) Structural organization of the MPDE3A catalytic domain (AAs 714-975), depicting conserved $\mathrm{Zn}^{++}-$binding domains (AAs 752-825 and 836-866) and translated sequence of exon 13 (AAs 856-923) deleted in the Pde3a-l- genome. (E) Western blot of solubilized proteins of heart, lung, liver, and fat pads (100 $\mu \mathrm{g} / \mathrm{lane})$ with rabbit anti-PDE3A (top) or anti-PDE3B (bottom) IgG.

tors block meiotic resumption and oocyte maturation in Xenopus oocytes, cultured murine, macaque, and human oocytes, and in vivo in cycling rats (in the latter, without affecting ovulation) (1, 22-27). Moreover, murine oocyte maturation, induced by microinjection of an active PDE (3), is associated with decreases in cAMP $(28,29)$. In Xenopus oocytes, progesterone-induced inhibition of adenylyl cyclase and IGF1-induced activation of cAMP hydrolysis (via an enzyme with properties of PDE3) both signal by reducing cAMP $(1,30,31)$. We previously reported that heterologous expression of PDE3A in Xenopus oocytes induced activation of mos translation and MAPK and resumption of meiosis (32).

To understand specific physiological roles of PDE3A, and to elucidate the role of cyclic nucleotides in oocyte maturation and female infertility, we generated mice deficient in PDE3A. These PDE3A-deficient mice represent the first murine genetic model demonstrating that disruption of CAMP signaling leads to meiotic arrest of oocytes and female infertility, that the processes of meiotic maturation and ovulation are dissociated, and that PDE3A is essential for oocyte maturation and subsequent fertilization.

\section{Results}

To establish a model for delineating PDE3A functions, we generated PDE3A-deficient mice by homologous recombination in embryonic stem cells (Figure 1). Since multiple PDE3A isoforms, generated from the single $P d e 3$ a gene, are found in cardiovascular tissues (33, 34), $P d e 3 a^{-/-}$mice were generated by a targeted disruption of exon 13, which encodes a portion of the PDE3A catalytic domain (Figure 1). As seen in Figure 1, mouse Pde3a (MPde3a) exon 13, encoding a portion of the second putative metal-binding site in the center of the PDE3A catalytic domain (Figure 1A), was replaced by the neomycin phosphotransferase II (NPTII) coding sequence (Figure 1B). Homologous recombination was confirmed by Southern blots (Figure 1C, top) or PCR of genomic DNA (Figure 1C, bottom). The mRNA of the rearranged gene, however, was transcribed and translated as shorter mutant PDE3A forms (Figure 1, D and E), lacking that portion of the catalytic domain encoded by exon 13 (Figure 1D). The immunoreactive, smaller, mutant PDE3A forms are expressed at low levels in $\mathrm{Pde} 3 \mathrm{a}^{-/-}$mice and are much less abundant than intact WT PDE3A (Figure 1E). Consistent with PDE3A being the predominant PDE in murine oocytes $(22,23)$ and PDE3B being absent from oocytes $(14,15)$, and with the mutant form of PDE3A being catalytically inactive, PDE3 activity was undetectable in isolated $P d e 3 a^{-/}$oocytes (Figure $2 \mathrm{~A}$ ), and cAMP content was greater in denuded $P d e 3 a^{-/-}$than in $P d e 3 a^{+/+}$oocytes $(P=0.003)$ (Figure $\left.2 \mathrm{~B}\right)$.

Because cells contain representatives of several PDE gene families, PDE3 activity in different tissue homogenates was measured (35) as that fraction of total PDE activity inhibited by $1 \mathrm{M}$ cilostamide, a specific PDE3 inhibitor. Cilostamide, however, inhibits both PDE3A and PDE3B isoforms with similar potency. As seen in Figure 2C, there was also almost complete loss of PDE3 activity in homogenates from $P d e 3 a^{-/}$lungs, indicating that PDE3A is the predominant PDE3 expressed in lung. PDE3 activity was also markedly reduced in homogenates from $P d e 3 \mathrm{a}^{-/-}$hearts. Consistent with relatively high expression of PDE3B in liver and adipose tissue, PDE3 activities were only slightly lower in those tissues from $P d e 3 a^{-/-}$ mice than from WT $P d e 3 a^{+/+}$mice (Figure 2C). Further investiga- 
A

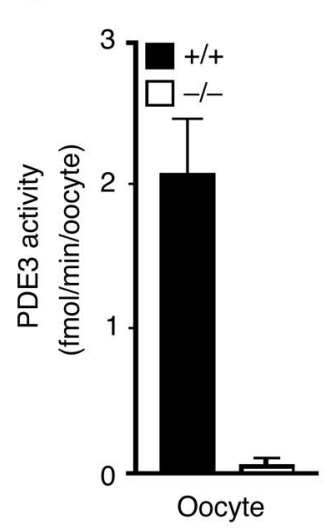

B

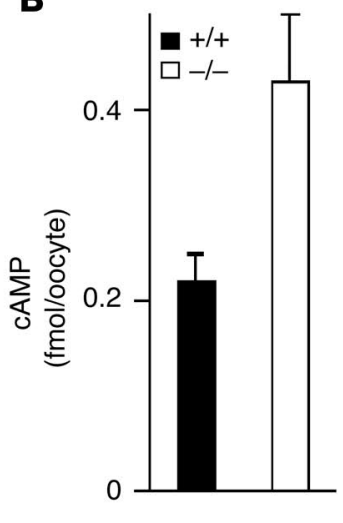

C

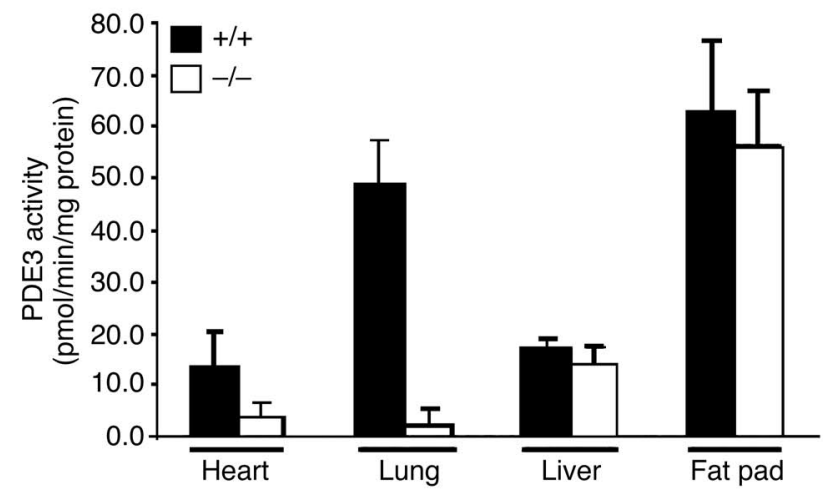

D
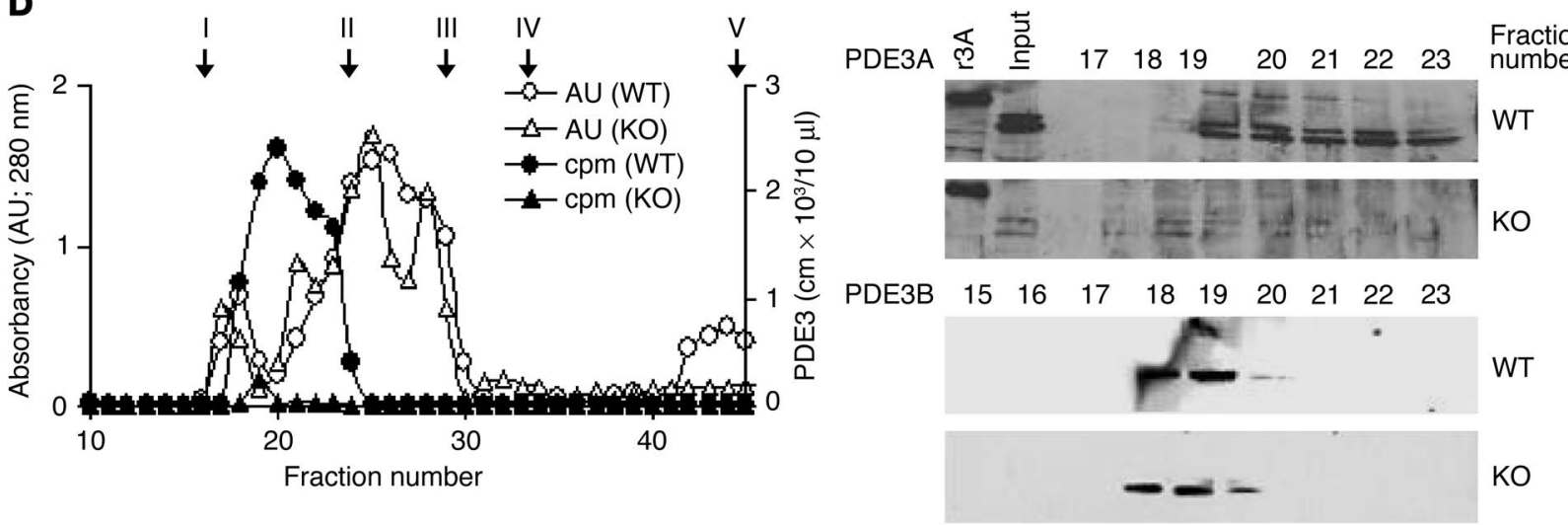

\section{Figure 2}

Oocyte cAMP content and PDE3 activities in tissues from $P d e 3 a^{+/+}$and $P d e 3 a^{-/-}$mice. (A) PDE activities in $P d e 3 a^{+/+}$and $P d e 3 a^{-/-}$oocytes. PDE activity was assayed in oocytes from $6 \mathrm{Pde} \mathrm{A}^{-/-}$and $6 \mathrm{Pde} \mathrm{a}^{+/+}$mice with $\left[{ }^{3} \mathrm{H}\right]$-cAMP as substrate as described $(22,23)$ and is reported as fmol cAMP hydrolyzed/min/oocyte (mean \pm SEM; $n=6$ ). (B) cAMP content in denuded $P d e 3 a^{-/}$and $P d e 3 a^{+/+}$oocytes. As described in Methods, oocytes from $11 \mathrm{Pde}^{+/++}$and $15 \mathrm{Pde}^{+\mathrm{a}^{-/}}$mice were assayed for cAMP content, reported as fmol cAMP/oocyte. (C) PDE3 activities in heart, lung, liver, and adipose tissues from $\mathrm{Pde} \mathrm{a}^{+/+}$and $\mathrm{Pde}_{\mathrm{C}} \mathrm{a}^{-/-}$mice. Homogenates were prepared and PDE3 activities assayed as described in Methods. Data are means \pm SEM of values (pmol cAMP hydrolyzed $/ \mathrm{min} / \mathrm{mg}$ protein), $n=6$ mice. (D) Gel filtration chromatography. Solubilized proteins ( 4 mg), prepared from lung tissues from $\mathrm{Pde} \mathrm{a}^{+/+}$or $\mathrm{Pde} 3 \mathrm{a}^{-/-}$mice in buffer containing $1 \% \mathrm{NP}-40$ as described in Methods, were subjected to gel filtration chromatography. Left panel: protein ( $\mathrm{AU} ; 280 \mathrm{~nm}$ ) (open circles, open triangles) and PDE3 activity (PDE3 cpm/10 $\mu$ l) (filled circles, filled triangles) in indicated fractions from $\mathrm{Pde} 3 \mathrm{a}^{+/+}$(WT, open circles, filled circles) and Pde $3 a^{-/-}$(KO, open triangles, filled triangles) mice; $>90 \%$ of the applied PDE3 activity was recovered in indicated fractions from $+/+$ mice (filled circles). Molecular weight standards: I, thyroglobulin; II, -globulin; III, ovalbumin; IV myoglobin; V, Vit B12. Right panel: Western blots of material applied (input $10 \mu$ I) and indicated fractions $(40 \mu \mathrm{l})$ from $+/+$ and $-/-$ mice with rabbit anti-PDE3A (upper panel) and anti-PDE3B (lower panel) IgG. Recombinant rat PDE3A (r3A) was used as positive control in PDE3A Western blots.

tion by gel filtration chromatography demonstrated that PDE3B could account for the residual low levels of PDE3 activity detected

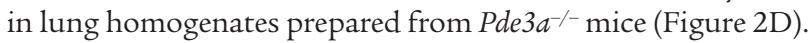

Mice lacking PDE3A were viable and exhibited no obvious growth or developmental deficiencies. Male $P d e 3 a^{-/-}$mice were fertile and produced viable offspring, whereas female $P d e 3 a^{-/}$mice were completely sterile, whether mated to $P d e 3 a^{-/-}$or $P d e 3 a^{+/+}$males (Table 1). Female $P d e 3 a^{+/-}$mice were also fertile, which indicates that the residual, catalytically inactive, shorter mutant PDE3A forms (cf. Figure 1, D and $\mathrm{E}$ ) did not interfere with oocyte function by acting as "dominant negative" PDE3A forms. Pde $3 \mathrm{a}^{-/-}$ovarian structure and morphology were unremarkable, with a normal complement of corpora lutea and antral follicles, which suggests normal folliculogenesis and ovulation (Figure 3, A-H). As also seen in Figure 3, I-L, after injection of female mice with pregnant mare serum gonadotropin (PMSG) and human chorionic gonadotropin (hCG), cumulus expansion was normal and observed in ovarian follicles of both $\mathrm{Pde} 3 \mathrm{a}^{+/+}$and $\mathrm{Pde} 3 \mathrm{a}^{-/-}$mice. Whereas the $P d e 3 a^{+/+}$oocyte progressed to metaphase, as evidenced by the presence of a metaphase spindle (Figure 3, I and J), the Pde $3 a^{-}$ - oocyte remained arrested in meiotic prophase I, as demonstrated by the persistence of the nuclear germinal vesicle $(\mathrm{GV})$, classified as the GV stage (Figure 3, K and L). Although Pde $3 a^{-/-}$mice exhibit normal mating behavior and spontaneous and PMSG/hCG-stimulated ovulation (Table 2), nonfertilized $P d e 3 a^{-/-}$oocytes retrieved from the ampulla (Table 2) also were arrested in meiotic prophase I (GV stage), as demonstrated by the persistence of the nuclear germinal vesicle (Figure 4B). After mating, two-cell embryos were collected from oviducts of $P d e 3 a^{+/+}$females (Table 2 and Figure 4A), whereas immature GV-stage oocytes with sperm in the perivitelline space were retrieved from $P d e 3 a^{-/}$oviducts (Figure 4B). Thus, sterility of $P d e 3 a^{-/-}$females, 
Table 1

Infertility in female Pde3a-- mice

\begin{tabular}{lccc}
$\mathbf{M}$ & $\mathbf{F}$ & $\begin{array}{c}\text { C57BL/6J-129/SvJ } \\
\text { Average litter size }\end{array}$ & $\boldsymbol{n}^{\mathbf{B}}$ \\
WT & WT & $7.9 \pm 2.9$ & 10 \\
WT & he & $6.5 \pm 2.0$ & 2 \\
WT & KO & $0 \pm 0$ & 4 \\
K0 & WT & $6.1 \pm 2.0$ & 7 \\
K0 & he & $7.2 \pm 2.0$ & 27 \\
K0 & KO & $0 \pm 0$ & 4 \\
he & he & $7.9 \pm 3.0$ & 7 \\
\hline
\end{tabular}

Amean \pm SEM, $n=4-27$ litters, resulting from matings of C57BL/6J-129/ SvJ Pde $3 a^{+/+}$(WT) and $P d e 3 a^{-/-}(\mathrm{KO})$ mice; ${ }^{B} n$ indicates numbers of litters. Identical results, i.e. infertility of $\mathrm{KO}$ females, were observed with $\mathrm{Pde} \mathrm{a}^{+/+}$and $\mathrm{Pde} 3 \mathrm{a}^{-/-}$mice resulting from crossing Black Swiss and c57BL/6J-129/SvJ mice. he, heterozygous.

which apparently exhibit normal estrous cycles, ovulation, and mating behavior, is most likely related to the inability of $\mathrm{Pde}^{\mathrm{a} \mathrm{a}^{-} \text {- oocytes }}$ to resume meiosis in response to the normal luteinizing hormone surge or exogenously administered gonadotropins.

As shown in Figure 4, C-H, immediately after harvesting from ovarian follicles (time 0), both Pde3a $a^{+/}$(Figure 4C) and Pde3a-/(Figure 4D) oocytes contained intact GV, an interphase-like distribution of microtubules, and perinucleolar condensation of chromatin (surrounded nucleolus [SN] conformation). After removal from follicles, $P d e 3 a^{+/+}$oocytes, but not $P d e 3 a^{-/}$oocytes, resumed meiosis and completed germinal vesicle breakdown (GVBD) by approximately 3 hours, which was followed by extrusion of polar body (PB) (Figure 5, A-C). After 20 hours in culture, $P d e 3 a^{+/+}$oocytes exhibited a well-defined spindle apparatus with condensed and aligned chromosomes typical of metaphase II (Figure $4 \mathrm{E})$. In contrast, even after 20 hours, denuded $P d e 3 a^{-/-}$oocytes did not resume meiosis in vitro and remained blocked at the GV stage, with an interphase pattern of dispersed tubulin and partially condensed chromatin (Figure 4F). MPF and MAPK were activated during spontaneous maturation (at 18 hours) of cultured $P d e 3 a^{+/+}$ oocytes, but not $P d e 3 a^{-/-}$oocytes (Figure 5D). Moreover, meiosis did not resume in cumulusoocyte complexes cultured up to 12 hours with or without follicle-stimulating hormone (FSH), although the hormonal treatment produced normal expansion of cumulus cells (data not shown). Thus, complete blockade of spontaneous or gonadotropin-induced meiotic resumption occurs in Pde $3 a^{-/}$oocytes.

Consistent with the absence of oocyte PDE3A, cAMP levels were higher in $\mathrm{Pde} 3 \mathrm{a}^{-/}$than in $P d e 3 \mathrm{a}^{+/+}$ oocytes (cf. Figure 2B). Given the proposed role of cAMP and PKA in maintenance of meiotic arrest (1-5), in vitro treatment of Pde $3 a^{-/}$oocytes with PKA inhibitors Rp-8-Br-cAMPS or adenosine-3', $5^{\prime}$-cyclic monophosphorothioate, Rp-isomer (Rp-cAMPS) induced resumption of meiosis (Figure 5E). As expected, incubation of $\mathrm{Pde}^{+/ /+}$oocytes with cilostamide, a PDE3 inhibitor, blocked GVBD (Fig-

\section{Figure 3}

ure $5 \mathrm{E}$ ), presumably due to high levels of cAMP and activation of PKA. Similar to effects of Rp-cAMPS in Pde3a $a^{-/}$oocytes, incubation of cilostamide-treated $\mathrm{Pde}^{+} \mathrm{a}^{+/}$oocytes with Rp-cAMPS (Figure 5E) or Rp-8-Br-cAMPS (data not shown) induced resumption of meiosis. As seen in Figure 4, G-H, after treatment with Rp-8-Br-cAMPS, both $\mathrm{Pde}^{+/ /+}$(Figure 4G) and $P d e 3 a^{-/}$oocytes (Figure $4 \mathrm{H}$ ) appeared as mature eggs at metaphase II. Resumption of meiosis in Pde $3 \mathrm{a}^{-/-}$ oocytes occurred after only a brief exposure to PKA inhibitors (Figure 5F). Treated $P d e 3 a^{-}-$oocytes exhibited activated MPF and MAPK (Figure 6A) and were competent for fertilization in vitro (Figure 6B). Microinjection of PKI or protein phosphatase cdc25b mRNA also initiated resumption of meiosis in Pde3a $a^{-/}$oocytes (Figure 6C).

\section{Discussion}

The PDE gene superfamily apparently encodes more than 50 PDE proteins (12). Some cells are relatively enriched in specific PDEs; these include oocytes $(22,23)$ and retinal rods and cones $(12)$, in which PDE3A and PDE6, respectively, are the predominant PDEs. Most cells, however, contain representatives of at least several PDE gene families and different subfamily isoforms from the same gene family, but in different amounts, proportions, and subcellular locations (12). Family-specific PDE inhibitors can pharmacologically define functions of individual PDEs and, in cells containing multiple PDEs, dissect out effects of specific PDEs in regulating specific signaling pathways and cellular functions. For example, PDE3 inhibitors, but not PDE4 inhibitors, increase insulin secretion in cultured pancreatic cells (HIT-T15 or HIT cells), despite greater effects of PDE4 inhibitors on cAMP content in these cells $(17,18)$. In the female reproductive system, differential cellular expression of PDE4 and PDE3 isoforms in granulosa cells and oocytes, respec-

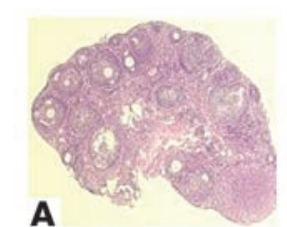

A
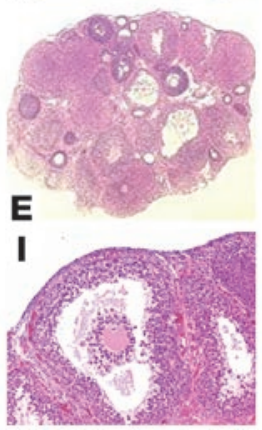
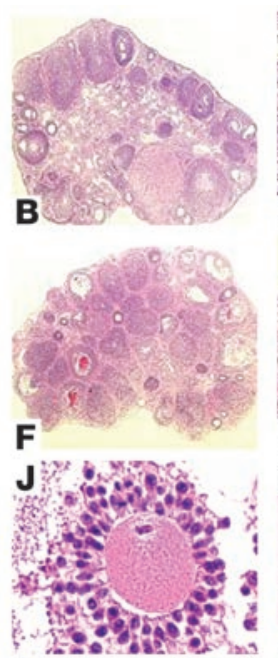
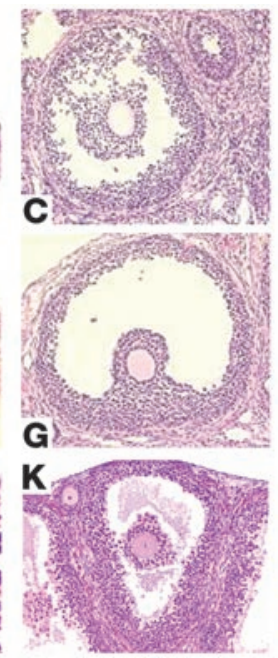

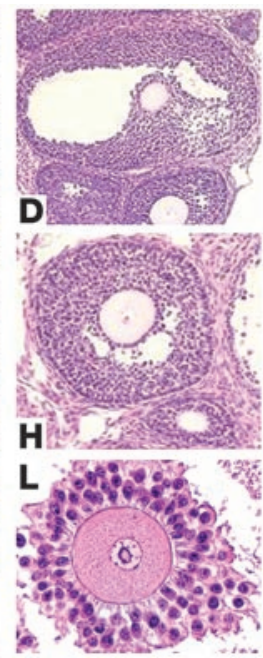

Histology of ovaries from $\mathrm{Pde} 3 \mathrm{a}^{+/+}$and $\mathrm{Pde} 3 \mathrm{a}^{-/-}$mice. (A-H) H\&E sections of ovaries harvested from C57BL/6J-129/SvJ females (3 months old), $P$ de $3 a^{+/+}$(A and C) or Pde3a ${ }^{-/}(\mathbf{B}$ and $\mathbf{D})$, or from females (5 weeks old) after induction of superovulation as described in Methods, $\mathrm{Pde}^{+/ /+}(\mathbf{E}$ and $\mathbf{G})$ or $\mathrm{Pde}^{+} \mathrm{a}^{-/-}(\mathbf{F}$ and $\mathbf{H})$. Magnification, $\mathbf{A}, \mathbf{B}, \mathbf{E}$, and $\mathbf{F}$ : $\times 4 ; \mathbf{C}, \mathbf{D}, \mathbf{G}$, and $\mathbf{H}: \times 20 . P d e 3 a^{-/-}$females exhibited normal ovaries and follicles, either in normal condition or following superovulation. (I-L) $P d e 3 a^{+/+}$or $P d e 3 a^{-/-}$females were injected with PMSG and hCG as described in Methods; 9 hours after injection with hCG, $\mathrm{H} \& \mathrm{E}$ sections were prepared. Note the expanded cumulus, which has lost contact with the follicle wall in both genotypes. Whereas the $\mathrm{Pde} \mathrm{a}^{+/+}$oocytes are in metaphase (with an evident spindle) (I and $\mathbf{J})$, the immature $P d e 3 a^{-/}$oocytes exhibit an intact nuclear membrane (GV stage) ( $\mathbf{K}$ and $\mathbf{L}$ ). 


\section{Table 2}

Absence of fertilization in $\mathrm{Pde} 3 \mathrm{a}^{-/}$oocytes following natural or induced ovulation

\begin{tabular}{|c|c|c|c|c|}
\hline \multicolumn{5}{|c|}{ Natural ovulation (C57BL/6J-129/SvJ) } \\
\hline$n^{\mathrm{A}}$ & Genotype & Ovulated eggs & Embryos & Oocytes \\
\hline 1 & WT & 10 & 10 & 0 \\
\hline 4 & KO & 28 & 0 & 28 \\
\hline \multicolumn{5}{|c|}{ Induced ovulation (C57BL/6J-129/SvJ) } \\
\hline$n^{\mathrm{A}}$ & Genotype & Ovulated eggs & Embryos & Oocytes \\
\hline 3 & WT & 90 & 90 & 0 \\
\hline 3 & KO & 122 & 0 & 122 \\
\hline
\end{tabular}

tively, seems to be important in the integrating signals involved in luteinizing hormone (LH) induction of oocyte maturation, which apparently involves opposing effects of cAMP in somatic and germ cells $(1,15)$. Actions of PDE4 inhibitors in follicle cells enhance effects of LH on oocyte maturation, whereas PDE3 inhibitors act directly in oocytes, increasing cAMP and suppressing meiotic progression $(1,15)$. In PDE4D KO mice, however, the rate of ovulation and, consequently, fertility, is reduced (36). Other reports further support the view that multiplicity of PDEs does not serve merely a survival or protective function, but that differentially regulated and targeted PDEs are critical for selective compartmentalization and modulation of cyclic nucleotide signals and responses $(37,38)$.

Analysis of the phenotypic characteristics of mice with a targeted disruption of the Pde3a gene indicates that, in oocytes, PDE3A
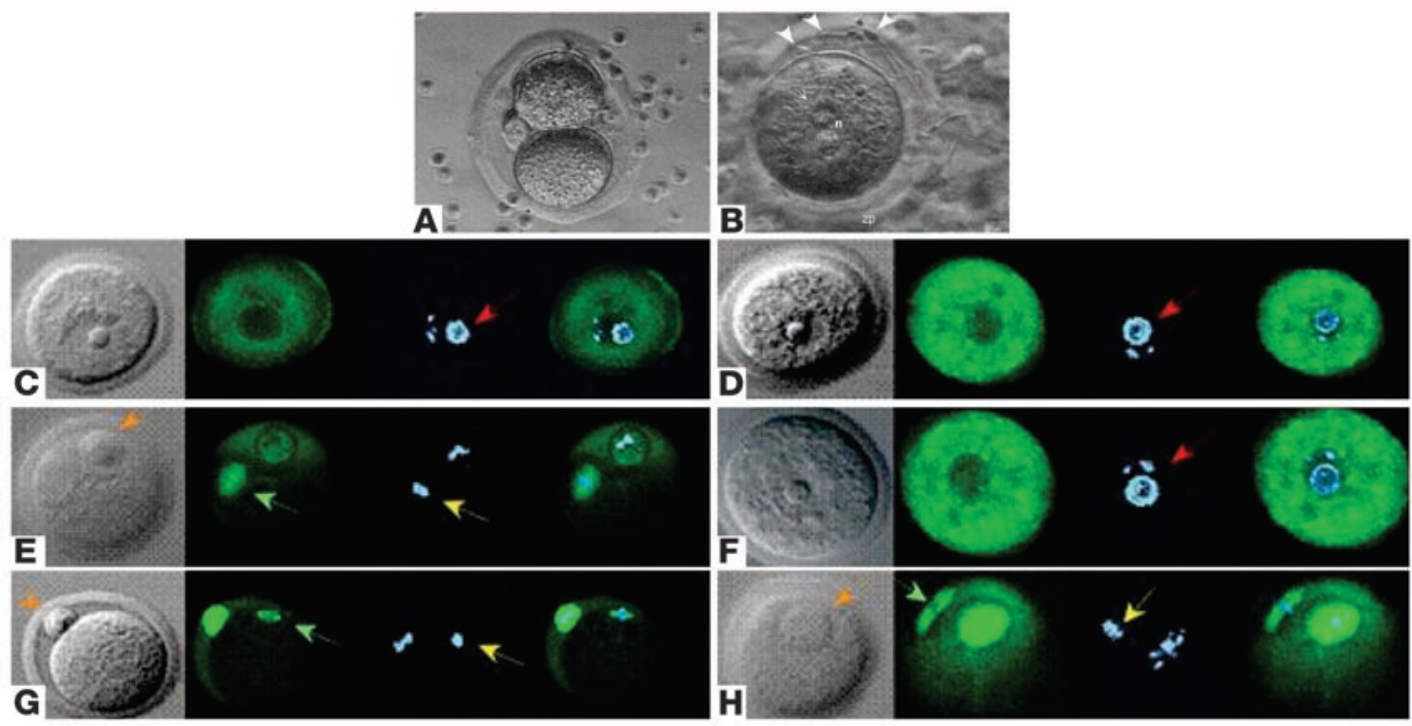

\section{Figure 4}

Maturation of $P d e 3 a^{+/+}$and $P d e 3 a^{-/-}$oocytes in vivo and in vitro. (A and B) Nomarski images of $P d e 3 a^{+/+}$embryos and nonfertilized, ovulated $P d e 3 a^{-/-}$oocytes. Following induced ovulation, and 24 hours after mating, $P d e 3 a^{+/+}$embryos and nonfertilized, ovulated $P d e 3 a^{-/-}$oocytes were harvested from oviducts of females as described in Methods. (A) Two-cell-stage embryos were observed in oviducts from Pde3a+/+ females. (B) Immature $P d e 3 a^{--}$oocytes were not fertilized and exhibited clear intact nuclear membranes (GV) (thin arrows) and nucleoli (n). Sperm (arrowheads) traversed the zona peillucida (zp) but did not fuse with the plasma membranes of immature GV stage oocytes. (C-H) Nomarski images and immunofluorescent staining of oocytes from $P d e 3 a^{+/+}$and $P d e 3 a^{-/-}$mice. $P d e 3 a^{+/+}(\mathbf{C})$ and $P d e 3 a^{-/-}$(D) oocytes were fixed immediately after isolation. $P d e 3 a^{+/+}(\mathbf{E}$ and $\mathbf{G})$ and $P d e 3 a^{-/-}(\mathbf{F}$ and $\mathbf{H})$ oocytes were incubated for 20 hours in maturation medium without $(\mathbf{E}$ and $\mathbf{F})$, or with $(\mathbf{G}$ and $\mathbf{H}$ ), $5 \mathrm{mM} \mathrm{Rp-8-Br-cAMPS.} \mathrm{In} \mathrm{each} \mathrm{row} \mathrm{from} \mathrm{left} \mathrm{to} \mathrm{right} \mathrm{are} \mathrm{shown} \mathrm{Nomarski} \mathrm{images,} \mathrm{antitubulin} \mathrm{immunofluorescent} \mathrm{staining} \mathrm{(green),} \mathrm{DAPI}$ immunofluorescent staining (blue), and merged images of anti-tubulin and DAPI staining. In these oocytes the chromatin nucleolar rim around the nucleoli (red arrows) and the interphase-like microtubules can be seen. After 20 hours, metaphase II-blocked oocytes show the chromosomes aligned at the metaphase plate (yellow arrows), microtubule spindle formation (green arrows), and PBs (orange arrow). For technical reasons, in $\mathbf{F}$, two different $P d e 3 a^{-1-}$ oocytes were used for Nomarski imaging and immunofluorescence staining. 

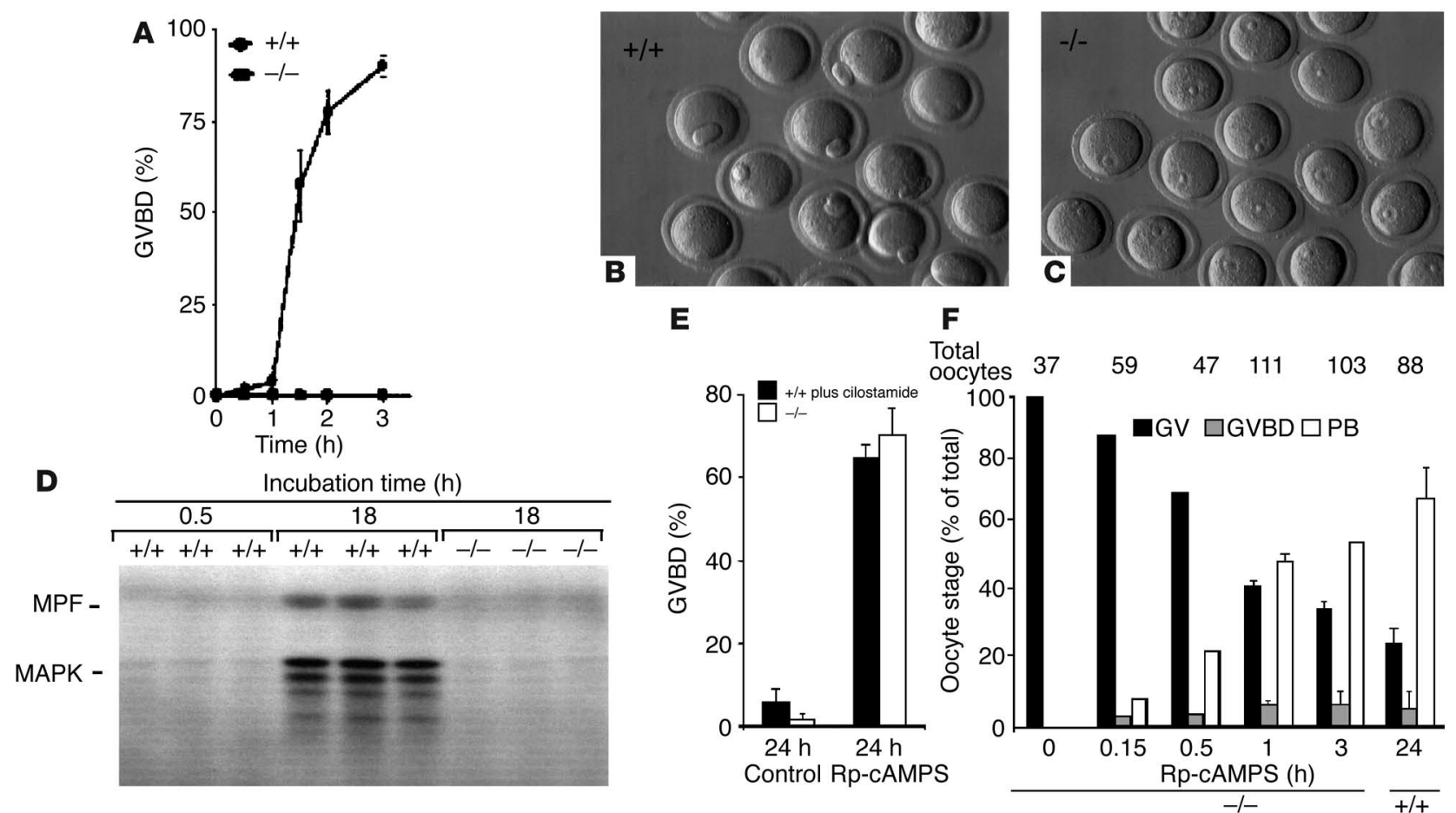

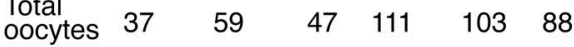

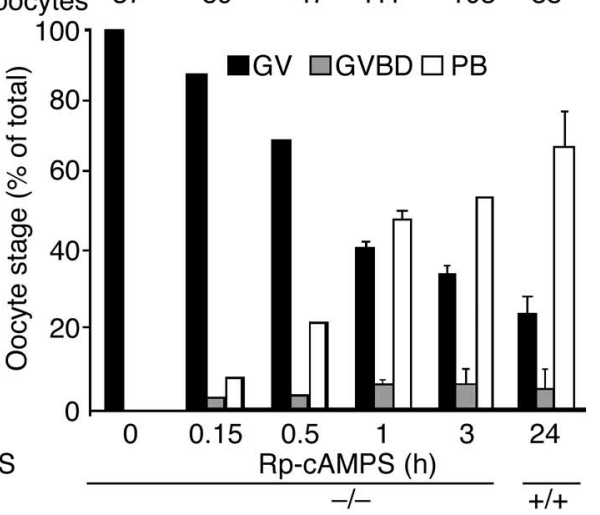

\section{Figure 5}

Regulation of maturation of cultured $P d e 3 a^{+/+}$and $P d e 3 a^{-/-}$ooctyes. (A-C) Time course of spontaneous maturation. (A) Denuded $P d e 3 a^{+/+}$, not $P d e 3 a^{-1}$, oocytes undergo spontaneous maturation (demonstrated by GVBD) within 3 hours in vitro. (B and C) After 20 hours, Pde3a ${ }^{+/+}$(B), but not $P d e 3 a^{-/-}$(C), oocytes exhibit GVBD and PBs. (D) Absence of MAPK and MPF activation in Pde3a ${ }^{-/}$oocytes. MPF and MAPK, assayed at indicated times as described in Methods, were activated $(18 \mathrm{~h})$ in $P d e 3 a^{+/+}$, but not $P d e 3 a^{-/-}$, oocytes. (E and F) Effects of PKA inhibitors on maturation of $P d e 3 a^{+/+}$and $P d e 3 a^{-/-}$oocytes. (E) Pde3a $a^{+/+}$(with $10 \mu \mathrm{M}$ cilostamide) and $P d e 3 a^{-/-}$oocytes were incubated for 24 hours without or with $5 \mathrm{mM}$ Rp-cAMPS before evaluation of GVBD. In the absence of Rp-cAMPS, spontaneous maturation was blocked in both Pde3a-l- and cilostamide-treated $P d e 3 a^{+/+}$oocytes. GVBD and meiosis were reinitiated to the same extent by Rp-cAMPS in Pde $3 a^{-/-}$oocytes and cilostamide-treated $\mathrm{Pde} \mathrm{a}^{+/+}$oocytes. (F) $\mathrm{Pde} 3 \mathrm{a}^{-/-}$and $\mathrm{Pde} 3 \mathrm{a}^{+/+}$oocytes were incubated for the indicated times with $5 \mathrm{mM} \mathrm{Rp}-8$-Br-cAMPS, washed twice in a drop $(50 \mu \mathrm{l})$ of maturation medium, and incubated without Rp-8-Br-cAMPS. After 24 hours, all oocytes were assessed for GVBD and PB formation. "Total oocytes" indicates the numbers incubated under each condition. Within 1 hour of treatment of $P d e 3 a^{-/-}$oocytes with Rp-8Br-cAMPS, meiosis was reinitiated, as monitored by the percent decrease in GV, and increase in GVBD and PB. Data at $0,1,3$, and 24 hours represent mean percent \pm one half of the range, in two separate experiments.

plays a unique role, which is apparently not replaced or functionally compensated for by other PDE gene families or by the other PDE3 family member, PDE3B. Inactivation of the Pde3a gene results in a phenotype characterized by female infertility. Despite normal ovarian structure, folliculogenesis, ovulation, and mating behavior, female PDE3A KO mice are sterile, most likely due to specific and direct effects of the absence of PDE3A in oocytes - i.e., inhibitory effects of elevated cAMP on meiotic progression and oocyte maturation and, consequently, the competency of oocytes for fertilization. Additional studies with PDE3A KO mice will undoubtedly prove useful in elucidating other physiological roles of PDE3A.

Targeted disruption of Pde4 genes has also similarly generated mice with unique phenotypes (36, 39-41). Analyses of these phenotypes support the concept that the ability of different PDEs to subserve different physiological roles is, at least in part, genetically determined. For example, PDE3B KO mice, although fertile and not frankly diabetic, demonstrate alterations in regulation of energy homeostasis and signs of insulin resistance (our unpublished data). Thus, discrete, nonoverlapping signaling pathways are disrupted when genes encoding specific PDEs are inactivated or when specific PDEs are pharmacologically inhibited, which thus sup- ports the concept that different PDEs are functionally nonredundant and regulate different $\mathrm{CAMP} / \mathrm{cGMP}$ pools and responses.

Although increases in CAMP and activation of PKA are crucial in the induction and maintenance of meiotic arrest, the precise targets and downstream effectors of cAMP signalling have not been completely defined $(1,42)$. Recent studies suggest that PKA may affect two parallel pathways that regulate activation of MPF (3, 10, 42, 43). PKA apparently blocks translation of Mos (the oocyte MAPK), perhaps by inhibiting polyadenylation of its mRNA (43). In frog oocytes, Mos activates MAPK, leading to inhibition of MYT1, a kinase that phosphorylates and inhibits $\operatorname{MPF}(3,10,42$, 43). In addition, PKA-catalyzed phosphorylation of CDC25 may result in its sequestration by $14-3-3$ and thus negatively regulate CDC25-induced activation of MPF (10).

The rapid reversal of cAMP/PKA-induced meiotic arrest by PKA inhibitors in Pde $3 \mathrm{a}^{-/-}$oocytes (cf. Figures 5 and 6) is consistent with the reported activation of PDE3A (23) and decrease in cAMP $(28,29)$ that apparently precede spontaneous or hCG-induced maturation of murine oocytes. Thus, a brief period of reduced PKA activity (via PKA inhibition in $P d e 3 a^{-/-}$oocytes or activation of PDE3A and reduction in cAMP and PKA activity in murine 


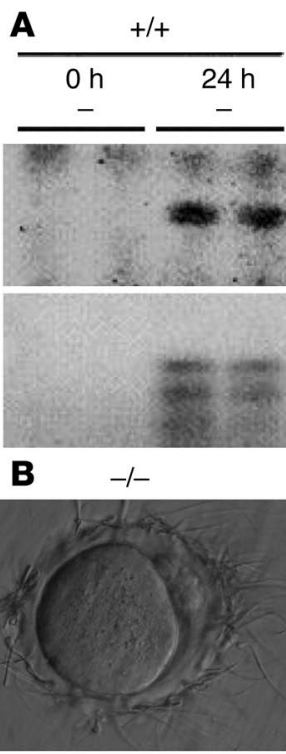

$4 \mathrm{~h}$
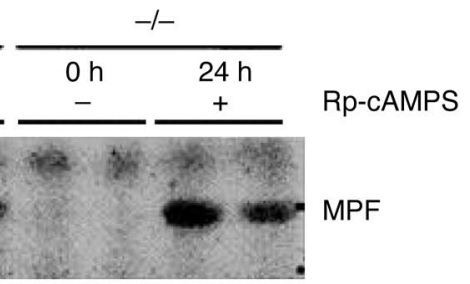

MAPK

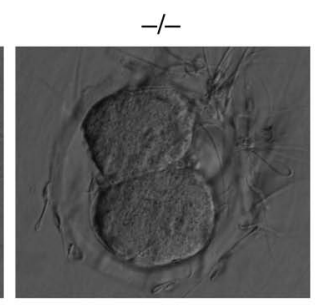

$24 \mathrm{~h}$
C

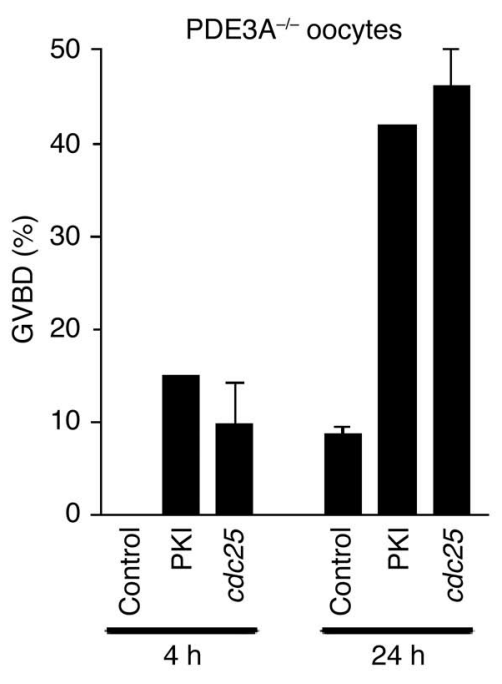

Taken together, these experiments strongly suggest that absence of PDE3A in oocytes leads to high levels of CAMP, persistent activation of PKA, and phosphorylation of critical regulatory effectors, resulting in inhibition of MPF/MAPK signals involved in resumption of meiosis and subsequent development of competency for fertilization (Figure 7). Under these conditions, the physiological signal that triggers meiosis in vivo is ineffective, which underscores the critical role of PDE3A in meiotic resumption and female fertility. Thus, $P d e 3 a^{-/-}$ mice provide a novel genetic model for studies of female sterility and present the possibility that some idiopathic infertility in women may be the result of mutations that cause inactivation of this gene. More importantly, the apparently reversible, perhaps "physiological," nature of the meiotic arrest in $P d e 3 a^{-/-}$ oocytes clearly suggests - along with earlier reported in vivo and in vitro effects of PDE3 inhibitors on meiotic progression and oocyte maturation $(26,27)$ - that PDE3A could be an excellent potential target for contraceptives (Figure 7). It should be pointed out that ovulation and oocyte maturation are complete-

oocytes) is sufficient to trigger resumption of meiosis. If cAMP is assumed to remain elevated in $P d e 3 a^{-/-}$oocytes after removal of the PKA inhibitors, reactivation of PKA apparently does not affect meiotic progression. From this, one may infer that PKA activity per se is not critical, but rather it is the temporal and spatial distribution and localization of cAMP signals and/or signaling pathways and modules $(37,38,44,45)$ that organize and orchestrate the signals that regulate meiotic arrest and progression. Research has indicated that during oocyte maturation, A-kinase-anchoring proteins (AKAPs) $(44,45)$ might compartmentalize, and thereby regulate actions of, PKA and other effector molecules, i.e., protein kinases and phosphatases and other scaffolding proteins. Whether PDE3A is physically targeted to these putative spatially segregated signaling modules (similar to the association of PDE4 isoforms with AKAP in regulating ryanodine-sensitive channels [ref. 46] or with $\beta$-arrestin in downregulation of the $\beta$-adrenergic receptor [ref. $47]$ ), and/or regulates their signaling output, is uncertain. These considerations are also consistent with recent studies indicating that some of the inhibitory effects of PKA on meiotic arrest may be independent of kinase activity and perhaps mediated via its direct interaction with and sequestration of critical regulatory effectors rather than via phosphorylation of these molecules (48). ly dissociated in the Pde $3 \mathrm{a}^{-/}$mouse, which emphasizes the concept that oocyte maturation can be targeted independently of somatic cells and without affecting the hormonal milieu. At the present time, however, use of PDE3 inhibitors, such as cilostamide or cilostazol, as contraceptives is not feasible, since inhibitors specific for PDE3A or PDE3B isoforms have not been developed, and methods to selectively target oocyte PDE3A are not available. Nevertheless, as outlined in Figure 7, $\mathrm{Pde} 3 \mathrm{a}^{-/-}$mice provide a valuable model in which to dissect and reconstitute signaling pathways downstream of cAMP that regulate meiosis in oocytes (and perhaps division and proliferation in other cAMP-responsive cells). It is also conceivable that some of these downstream effectors and pathways will offer more accessible and efficacious contraceptive targets.

\section{Methods}

Generation of Pde $3 a^{-/-}$mice. Pde $3 a^{-/-}$mice were generated by a targeted disruption of exon 13, which encodes a portion of the second putative metal-binding site in the center of the PDE3A catalytic domain. The pKO Scrambler NTK Vector-1903 (Stratagene, La Jolla, California, USA) was used to construct the replacement vector. An approximately 16-kb SalI genomic DNA fragment, containing five putative exons (exons 10-14) that encode much of the catalytic domain 


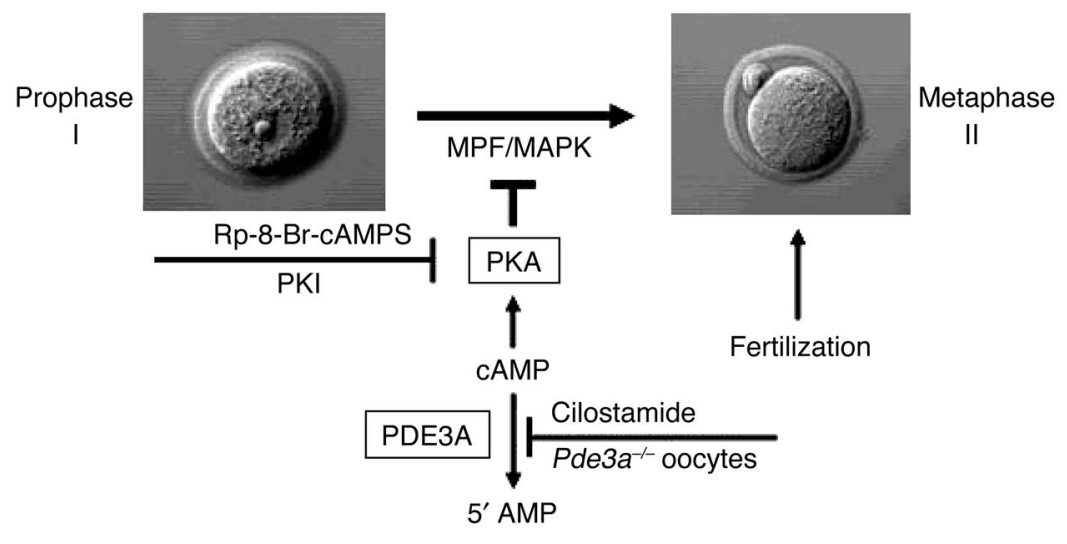

Figure 7

Role of PDE3A in oocyte maturation and female infertility. $P d e 3 a^{-/-}$mice represent what we believe to be the first genetic model indicating that that PDE3A is necessary for meiotic resumption in mouse oocytes and that, in the absence of oocyte PDE3A, increased cAMP and the consequent disruption of cAMP-signaling can lead to female infertility, presumably via PKA-catalyzed phosphorylation of key regulatory effectors that result in inhibition of MPF/MAPK-induced oocyte maturation. Our results with PKA inhibitors, such as Rp-8-Br-cAMPS and PKI, are consistent with PKA playing a major role in maintaining meiotic arrest at prophase I and thereby preventing meiotic progression to metaphase II and consequent development of competency for fertilization. The apparently reversible nature of the meiotic arrest in $\mathrm{Pde} \mathrm{a}^{-/-}$oocytes clearly suggests, along with reported effects of PDE3 inhibitors, such as cilostamide, on oocyte maturation (22-27), that oocyte PDE3A could represent an excellent potential target for contraceptives. genome, DNA was digested with BamHI, separated by agarose-gel electrophoresis, and hybridized with a ${ }^{32} \mathrm{P}-$ labeled probe designed to detect intron 10 , upstream from fragment A. Restriction fragments of approximately $12 \mathrm{~kb}$ and approximately $7.5 \mathrm{~kb}$ from $P d e 3 a^{+/+}$and $P d e 3 a^{-/-}$mice, respectively, were predicted and observed. The PCR primers designed to detect the normal $(+)$ allele (forward primer [FP]: 5'-TGCTATACAACGACCGTTCT$3^{\prime}$, reverse primer (RP): 5'-ATGACTAGGAAGCGGAAGTG-3') amplified exon 13 ( 136 bp), while PCR primers designed to detect the mutant (-) allele (FP: 5'- GATGGCTGGCAACTAGAAGG-3', RP: 5'-CATACGCTTGATCCGGCTAC-3') amplified the NPTII coding sequence ( $487 \mathrm{bp})$. Reactions were conducted using the Advantage GCcDNA polymerase mix (BD Biosciences, San Jose, California, USA) in the GeneAmp 9700 thermal cycler (Applied Biosystems, Foster City, California, USA), for 1 minute at $94^{\circ} \mathrm{C}, 10$ seconds at $94^{\circ} \mathrm{C}$, 45 seconds at $60^{\circ} \mathrm{C}$, and 2 minutes at $68^{\circ} \mathrm{C}$ for 35 cycles, and final extension, 7 minutes at $68^{\circ} \mathrm{C}$.

Collection and analysis of oocytes and embryos. $\mathrm{Pde} \mathrm{a}^{+/+}$and $\mathrm{Pde} 3 \mathrm{a}^{-/-} \mathrm{C} 57 \mathrm{BL} / 6 \mathrm{~J}-129 / \mathrm{SvJ}$ mice were generated and maintained and studies performed in accord with protocols approved by animal care and use committees at NHLBI, NIH, and Stanford University School of Medicine. After mice of MPDE3A, was isolated from a 129/SvJ FIXII mouse genomic library (Stratagene), using a $\left.{ }^{32} \mathrm{P}\right]$-labeled probe generated from a cDNA clone containing the catalytic domain of rat PDE3A. A 7.0$\mathrm{kb}$ SacI DNA fragment containing putative exons $11-14$ was subcloned from this original clone into pUC18 ( $\mathrm{SacI}$ site). This $7.0-\mathrm{kb}$ genomic subclone includes an approximately $1.5-\mathrm{kb}$ AocI restriction fragment that contains exon 13. Two segments, SacI-AocI ( $2.0 \mathrm{~kb}$, called fragment A) and AocI-SacI ( $3.5 \mathrm{~kb}$, called fragment B) were amplified by PCR and purified. Fragment A was digested with Ecl136II and EcoRI; fragment B, with BamHI and Ecl136II. These were sequentially cloned into the two polylinker sites of the $\mathrm{pKO}$ Scrambler NTK vector upstream and downstream of the region containing the NPTII coding sequence (Neo), the phosphoglycerol kinase (PGK) promoter, and the bovine growth hormone (BGH) polyadenylation (polyA) signal. The targeting vector thus consisted of fragment A containing MPde3a exons 11 and 12, the NPTII coding sequence, fragment B containing MPde $3 a$ exon 14, and the TK coding sequence. The vector was linearized and electroporated into 129/SvJ ES cells (Genome Sciences, St. Louis, Missouri, USA) where, by homologous recombination, MPde 3 a exon 13 was replaced by the NPTII coding sequence. Positive ES cell clones, identified by Southern blots and PCR, were microinjected into C57BL/6J blastocysts and implanted into pseudopregnant females. The resulting chimera was mated with $\mathrm{C} 57 \mathrm{BL} / 6 \mathrm{~J}$ to produce the $\mathrm{F}_{1}$ generation. $F_{1} P d e 3 a^{+/-}$heterozygous mice were mated to generate $\mathrm{Pde}^{-/-}$mice (designated as C57BL/6J-129/SvJ). For some of the experiments described herein, C57BL/6J-129/SvJ mice were mated with Black Swiss mice (Taconic Farms, Germantown, New York, USA) to generate Black Swiss/C57BL/6J-129/SvJ mice.

To confirm the MPde3a genetic rearrangement, DNA was extracted from tail samples and analyzed by Southern blots and PCR. Since the Neo sequence introduced a BamH1 site into the Pde $3 \mathrm{a}^{-/-}$
(3-6 weeks old) were sacrificed by asphyxiation $\left(\mathrm{CO}_{2}\right)$, ovaries were harvested, placed in maturation medium (MEM [Invitrogen Corp., Carlsbad, California, USA] with $2 \mathrm{mM}$ L-glutamine [Invitrogen Corp.], 25 mM HEPES [Sigma-Aldrich, St. Louis, Missouri, USA], $100 \mathrm{U} / \mathrm{ml}$ penicillin [Invitrogen Corp.], $100 \mu \mathrm{g} / \mathrm{ml}$ streptomycin [Invitrogen Corp.], $0.23 \mathrm{mM}$ sodium pyruvate [Sigma-Aldrich], and $3 \mathrm{mg} / \mathrm{ml}$ BSA [Sigma-Aldrich]), and punctured with a fine needle to release cumulus-oocyte complexes from the antral follicles. Denuded oocytes were obtained by repeated pipetting with a pulled Pasteur pipette and, after washing, were incubated under embryotested mineral oil (Sigma-Aldrich) for indicated times in a drop $(0.05 \mathrm{ml})$ of maturation medium without or with the indicated concentrations of Rp-8-Br-cAMPS (Calbiochem; EMD Biosciences, La Jolla, California, USA) or Rp-cAMPS in a $5 \% \mathrm{CO}_{2}$ atmosphere at $37^{\circ} \mathrm{C}$. To induce "superovulation," females ( 6 to 12 weeks old) were injected with $5 \mathrm{U} /$ mouse of pregnant mare serum gonadotropin (PMSG) (Sigma-Aldrich) and, 44-46 hours later, injected intraperitoneally) with $5 \mathrm{U} /$ mouse of hCG (Cortex Biochem, San Leandro, California, USA). In some experiments, female mice were sacrificed 9 hours after hCG injection; ovaries were collected, fixed in Bouin's solution, embedded, sectioned stained with H\&E, and analyzed for the presence of cumulus expansion and progression of oocyte meiosis in vivo. In other experiments, after hCG injection, females were caged with males, and the following morning, after being checked for the presence of vaginal plugs, were sacrificed by asphyxiation $\left(\mathrm{CO}_{2}\right)$. Oviducts were dissected, ovulated oocytes and two-cell-stage embryos were collected and incubated in maturation medium, and oocytes were examined for their meiotic stage under a dissecting stereomicroscope (model Stemi SV6; Carl Zeiss Inc., Thornwood, New York, USA). Oocytes showing clear nuclear membranes (GV) and nucleoli were classified as GV stage; those without visible nuclear structure and exhibiting GVBD were classified as 
GVBD stage; and metaphase II-arrested oocytes, with a PB, were classified as PB stage (27). After spontaneous or induced ovulation, the ovulated cells were examined; those at the two-cell stage were classified as embryos, whereas those still exhibiting a clear GV were defined as GV stage ovulated oocytes. Progression of meiotic maturation of denuded oocytes in vitro was scored by monitoring GVBD with an inverted microscope fitted with a Hoffman contrast lens.

Immunofluorescence. Twenty to 30 oocytes were fixed for 1 hour at room temperature (rt) in $2 \%$ paraformaldehyde in PBS, washed 5 times in blocking solution (PBS, pH7.4, containing 0.3\% BSA [Sigma-Aldrich] and $100 \mathrm{mM}$ glycine [ICN Biomedicals Inc., Costa Mesa, California, USA)]), permeabilized with blocking solution containing $0.1 \%$ Triton X-100 (Sigma-Aldrich), washed 3 times in blocking solution, and incubated 1 hour (rt) under embryo-tested mineral oil (Sigma-Aldrich) in $0.05 \mathrm{ml}$ of anti- $\alpha$-tubulin antibody (Accurate Chemical and Scientific Corp., Westburn, New York, USA), which had been diluted 1:100 in blocking solution. After five washes in blocking solution, the oocytes were incubated for 1 hour (rt) in $0.05 \mathrm{ml}$ of the secondary, Alexa Fluor 488-conjugated anti-rat antibody (Molecular Probes, Eugene, Oregon, USA), and washed 5 times. After 10 minutes in PBS, pH 8.1/glycerol (1:1 $\mathrm{vol} / \mathrm{vol}$ ), the oocytes were mounted in mounting medium (DAPI; Vectashield, Burlingame, California, USA) using a Hybaid Easyseal frame (Continental Lab Products, San Diego, California, USA) with regular glass slides and coverslips and viewed with a confocal microscope (Leica Microsystems, Heidelberg, Germany).

$P D E$ activity measurements. Denuded oocytes from $P d e 3 a^{-/-}$and $P d e 3 a^{+/+}$mice (20 for each PDE assay) were collected within 30 minutes after follicle puncture in Leibowitz's L-15 medium (Invitrogen Corp., Grand Island, New York, USA) with 5\% FBS and $100 \mathrm{IU} / \mathrm{ml}$ penicillin/streptomycin, washed, and frozen in PBS (3 $\mu \mathrm{l})$. Immediately before assay, $20 \mu \mathrm{l}$ of IPA buffer $(10 \mathrm{mM}$ sodium phosphate buffer, pH 7.2, $50 \mathrm{mM} \mathrm{NaF}, 150 \mathrm{mM} \mathrm{NaCl}, 2$ mM EDTA, $5 \mathrm{mM}$ mercaptoethanol, $30 \mathrm{mM}$ pyrophosphate, $3 \mathrm{mM}$ benzamidine, 5 $\mu \mathrm{g} / \mathrm{ml}$ leupeptin, $20 \mu \mathrm{g} / \mathrm{ml}$ pepstatin, $2 \mathrm{mM}$ PMSF, $1 \mu \mathrm{M}$ microcystin, and $0.5 \%$ Triton X-100) were added. Samples were centrifuged at $12,000 \mathrm{~g}$ at $4^{\circ} \mathrm{C}$ for 30 minutes, supernatants collected, and PDE activity was measured for 20 minutes.

After sacrifice of mice by asphyxiation $\left(\mathrm{CO}_{2}\right)$, heart, lung, liver, and fat pads were dissected from 3-3.5-month-old C57BL/6J-129/ SvJ males, quickly washed in ice-cold PBS, and homogenized (5 $\mathrm{ml} / \mathrm{g}$ tissue) in buffer (50 mM HEPES, pH 7.5 [Sigma-Aldrich], 25 $\mathrm{mM} \mathrm{KCl}$ [Sigma-Aldrich], $5 \mathrm{mM} \mathrm{MgCl} 2$ [Quality Biological Inc., Gaithersburg, Maryland, USA], protease inhibitor cocktail tablets [Roche, Nutley, New Jersey, USA]) with a rotor-stator homogenizer (Omni International, Marietta, Georgia, USA) at 30,000 rpm (15 to 90 seconds, on ice), followed by homogenization (on ice, 20 strokes in a glass Dounce tissue grinder [B pestle; Thomas Scientific, Swedesboro, New Jersey, USA]) and sonification (on ice, 20 pulses, $40 \%$ duty cycle, output scale 4 ). NP-40 (Calbiochem) ( $1 \%$ final) was then added and samples incubated (on ice, 1 hour), before centrifugation $\left(15,000 \mathrm{~g}, 20\right.$ minutes, $\left.4^{\circ} \mathrm{C}\right)$. Supernatants (total tissue lysates) were used for PDE assays (35) or gel filtration chromatography (FPLC-superose 12; AKTA FPLC System; Amersham-Pharmacia Biotech Inc., Piscataway, New Jersey, USA). For PDE assays, samples (usually $5-15 \mu \mathrm{g}$ protein in $100 \mu \mathrm{l}$ ) were incubated for 10 minutes in a total volume of $0.3 \mathrm{ml}$ containing $50 \mathrm{mM}$ HEPES, $\mathrm{pH}$ 7.4, $100 \mu \mathrm{M}$ EGTA, $8.3 \mathrm{mM} \mathrm{MgCl} 2$, and $\left[{ }^{3} \mathrm{H}\right]$-cAMP. PDE3 activity is that portion of total PDE activity inhibited by $1 \mathrm{mM}$ cilostamide (Calbiochem), a specific PDE3 inhibitor. Inhibitor vehicle, DMSO
(Sigma-Aldrich), added in equal quantities to samples without inhibitors, did not alter PDE activity. Protein was determined by BCA protein assay (Pierce, Rockford, Illinois, USA).

Western blots. Samples of solubilized tissue homogenates $(\sim 100$ mg protein) were subjected to SDS-PAGE (4-12\% Tris-Glycine gels [Invitrogen Corp., Carlsbad, California, USA]). After electrophoretic transfer, nitrocellulose membranes were blocked overnight at $4^{\circ} \mathrm{C}$ in T-PBS $(0.05 \%$ Tween 20 [Bio-Rad Laboratories, Hercules, California, USA] in PBS) containing 5\% non-fat dry milk (Bio-Rad Laboratories) and 1\% BSA, incubated 1-4 hours with the indicated primary antibody diluted in T-PBS $/ 5 \%$ milk, washed and incubated 1 hour with HP-conjugated secondary antibody against rabbit IgG (Amersham-Pharmacia Biotech Inc.) diluted 1:4000 in T-PBS. The signal was detected using ECL-Plus Detection System (AmershamPharmacia Biotech Inc.).

Primary antibodies, which were purified by chromatography on DEAE columns, included: rabbit IgG raised against a peptide corresponding to AAs 424-460 (regulatory domain) of human PDE3A, diluted 1:400 in T-PBS/5\% milk; rabbit IgG raised against a peptide corresponding to AAs 2-18 (N-terminal domain) of rat PDE3B, diluted 1:200 in T-PBS $/ 5 \%$ milk.

Measurement of cAMP content. Groups of 50 denuded oocytes were collected in L-15 medium, quickly washed, and frozen in PBS $(3 \mu \mathrm{l})$. After thawing and extraction with $100 \mu \mathrm{l}$ of $0.1 \%$ trichloroacetic acid in $95 \%$ ethyl alcohol, followed by centrifugation $\left(800 \mathrm{~g}, 30 \mathrm{~min}, 4^{\circ} \mathrm{C}\right)$, the supernatant was dried, and the residue dissolved in PBS $(100 \mu \mathrm{l})$. After acetylation, cAMP content was measured by radioimmunoassay (8).

Maturation-promoting factor (MPF) and MAPK activity measurements. Harvested oocytes were incubated for the indicated times prior to in vitro assay of MPF and MAPK as described (49), using histone H1 and myelin basic protein (MBP) as substrates, respectively. Briefly, 3 denuded oocytes (in $1.5 \mu \mathrm{l}$ of maturation medium) were immediately frozen on dry ice in $3.5 \mu \mathrm{l}$ of lysis buffer $(7 \mu \mathrm{g} / \mathrm{ml}$ aprotinin, $7 \mu \mathrm{g} / \mathrm{ml}$ leupeptin, $7 \mathrm{mM}$ p-nitrophenyl phosphate, $14 \mathrm{mM} \beta$-glycerophosphate, $70 \mu \mathrm{M}$ sodium orthovanadate, and $3.5 \mathrm{mM}$ EGTA) and stored at $-80^{\circ} \mathrm{C}$ prior to assay ) $10 \mu \mathrm{l}$ final vol, $30 \mathrm{~min}$ at $30^{\circ} \mathrm{C}$, $2 \mathrm{mg} / \mathrm{ml}$ histone [type III-S], $0.5 \mathrm{mg} / \mathrm{ml} \mathrm{MBP}$, and $500 \mu \mathrm{Ci} / \mathrm{ml}$ $\left[\gamma^{32} \mathrm{P}\right]$ ATP $[3,000 \mathrm{Ci} / \mathrm{mmol}$; Amersham-Pharmacia Biotech Inc.]). Reactions were terminated and proteins separated by SDS-PAGE (15\% gels), followed by gel drying and exposure to x-ray film.

In vitro fertilization. Denuded $P d e 3 a^{-/-}$oocytes were exposed to 5 mM Rp-cAMPS in maturation medium for 2 hours, washed, and incubated overnight at $37^{\circ} \mathrm{C}$ in $\mathrm{L}-15$ medium supplemented with $5 \%$ fetal bovine serum and $100 \mathrm{IU} / \mathrm{ml}$ penicillin/streptomycin. After 20 hours, oocytes at MII stage were incubated with capacitated sperm in modified KSOM embryo culture medium containing $5.6 \mathrm{mM}$ glucose and $4 \mathrm{mg} / \mathrm{ml} \mathrm{BSA}$. After 4 hours, oocytes and attached sperm were transferred to fresh medium and further incubated at $37^{\circ} \mathrm{C}$ in $5 \% \mathrm{CO}_{2}$ for 20 hours.

\section{Acknowledgments}

Marco Conti is supported in part by The National Institute of Child Health and Human Development, NIH, though a cooperative agreement (U54-HD31398), as part of the Specialized Cooperative Centers Program in Reproduction Research. We also wish to thank Martha Vaughan (NHLBI) for her critical reading of the manuscript and Faiyaz Ahmad (NHLBI) and Tanya Hoodbhoy (National Institute of Diabetes and Digestive and Kidney Diseases) for advice and technical assistance. 
Received for publication April 6, 2004, and accepted in revised form May 18, 2004.

Address correspondence to: Vincent Manganiello, Section on Biochemical Physiology, P-CCMB, NHLBI, NIH, Bldg 10, Rm 5N307, 9000 Rockville Pike, Bethesda, Maryland 20892, USA. Phone: (301) 496-1770; Fax: (301) 402-1610; E-mail: ManganiV@nhlbi.nih.gov.

1. Conti, M., et al. 2002. Role of cyclic nucleotide signaling in oocyte maturation. Mol. Cell. Endocrinol. 187:153-159.

2. Bornslaeger, A.E., and Schultz, R.M. 1985. Regulation of mouse oocyte maturation: effect of elevating cumulus cell cAMP on oocyte cAMP levels. Biol. Reprod. 33:698-704.

3. Nebreda, A.R., and Ferby, I. 2000. Regulation of the meiotic cell cycle in oocytes. Curr. Opin. Cell Biol. 12:666-675.

4. Downs, S.M., and Hunzicker-Dunn, M. 1995. Differential regulation of oocyte maturation and cumulus expansion of mouse oocyte-cumulus cell complex by site selective analogs of cAMP. Dev. Biol. 172:72-85

5 Qian, Y.-W., Erikson, E., Taieb, F.E., and Maller, J.L. 2001. The Polo-like kinase Plx1 is required for activation of the phosphatase CDC 25C and cyclin B-CDC2 in Xenopus oocytes. Mol. Biol. Cell. 12:1791-1799.

6. Eppig, J.J. 1991. Intercommunication between mammalian oocytes and companion somatic cells. Bioessays. 13:569-574.

7. Aktas, H., Leibfried-Rutledge, M.L., and First, N. 2003. Meiotic state of bovine oocytes is regulated by interactions between cAMP, cumulus and granulosa. Mol. Reprod. Dev. 65:336-343.

8. Horner, K., et al. 2003. Rodent oocytes express an active adenylyl cyclase required for meiotic arrest. Dev. Biol. 258:385-396.

9. Mehlmann, L.M., Jones, T.L.Z., and Jaffe, L.A. 2002. Meiotic arrest in the mouse follicle maintained by a Gs protein in the oocyte. Science. 297:1343-1345.

10. Duckworth, B.C., Weaver, J.S., and Ruderman, J.V. 2002. G2 arrest in Xenopus oocytes depends on phosphorylation of CDC25 by protein kinase Proc. Natl. Acad. Sci. U. S. A. 99:16794-16799.

11. Lincoln, A.J., et al. 2002. CDC25b phosphatase is required for resumption of meiosis during oocyte maturation. Nat. Genet. 30:446-449.

12. Francis, S.H., Turko, I.V., and Corbin, J.D. 2001. Cyclic nucleotide phosphodiesterases: relating structure and function. Prog. Nucleic Acid Res. Mol. Biol. 65:1-52.

13. Shakur, Y., et al. 2001. Regulation and function of the cyclic nucleotide phosphodiesterase (PDE3) gene family. Prog. Nucleic Acid Res. Mol. Biol. 66:241-277.

14. Reinhardt, R.R., et al. 1995. Distinct anatomical patterns of gene expression for cGMP-inhibited cyclic nucleotide phosphodiesterases [erratum 1997, 99:551]. J. Clin. Invest. 95:1528-1538.

15. Tsafriri, A., Chun, S.Y., Zhang, R., Hsueh, J.W., and Conti, M. 1996. Oocyte maturation involves compartmentalization and opposing changes of cAMP levels in follicular somatic and germ cells: studies using selective phosphodiesterase inhibitors. Dev. Biol. 178:393-402.

16. Degerman, E., et al. 2004. Role for phosphodiesterase $3 \mathrm{~B}$ in regulation of lipolysis and insulin secretion. In Diabetes Mellitus: A Fundamental and Clinical Text. 3rd edition. D. LeRoith, S.I. Taylor, and J.M. Olefsky, editors. Lippincott-Raven Publishers. Philadelphia, Pennsylvania, USA. 373-383.

17. Zhao, A., Zhao, H., Teague, J., Fujimoto, W., and Beavo, J.A. 1997. Attenuation of insulin secretion by IGF1 is mediated though activation of

S. Masciarelli and K. Horner contributed equally to characterization of the phenotype of PDE3A $\mathrm{A}^{-/-}$mice.

The PDE3A/PDE3B nomenclature in this report conforms to that suggested by a PDE nomenclature group (50). In an earlier report (14), the PDE3A/PDE3B nomenclature had been reversed. An erratum (see ref. 14) was published to correct and clarify this nomenclature discrepancy.

phosphodiesterase 3B. Proc. Natl. Acad. Sci. U. S. A. 93:14188-14192.

18. Zhao, A.Z., Bornfeldt, K.E., and Beavo, J.A. 1998. Leptin inhibits insulin secretion by activation of phosphodiesterase 3B. J. Clin. Invest. 102:869-873.

19. Zhao, A.Z., et al. 2000. Leptin induces insulinlike signaling that antagonizes cAMP elevation by glucagon in hepatocytes. J. Biol. Chem. 275:11348-11354.

20. Harndahl, L., et al. 2002. Important role of phosphodiesterase $3 \mathrm{~B}$ for the stimulatory action of cAMP on pancreatic beta-cell exocytosis and release of insulin. J. Biol. Chem. 277:37446-37455.

21. Harndahl, L., et al. 2004. Beta-cell-targeted overexpression of phosphodiesterase $3 \mathrm{~B}$ in mice causes impaired insulin secretion, glucose intolerance and deranged islet morphology. J. Biol. Chem. 279:15214-15222.

22. Shitsukawa, K., et al. 2001. Cloning and characterization of the cyclic guanosine monophosphateinhibited phosphodiesterase PDE3A expressed in mouse oocyte. Biol. Reprod. 65:188-196.

23. Richard, F.J., Tsafriri, A., and Conti, M. 2000. Role of phosphodiesterase type $3 \mathrm{~A}$ in rat oocyte maturation. Biol. Reprod. 65:1444-1451.

24. Sadler, S.E. 1991. Type III phosphodiesterase plays necessary role in the growth-promoting actions of insulin, IGF1 and Ha-p21ras in Xenopus laevis oocytes. Mol. Endocrinol. 5:1939-1946.

25. Jensen, J.T., et al. 2002. Phosphodiesterase 3 inhibitors selectively block resumption of meiosis by macaque oocytes in vitro. Hum. Reprod. 17:2079-2084.

26. Nogueira, D., Cortvrindt, R., DeMatos, D.G., Vanhoutte, L., and Smitz, J. 2003. Human oocytes reversibly arrested in Prophase I by phosphodiesterase Type 3 inhibitor in vitro. Biol. Reprod. 69:2045-2052.

27. Wiersma, A., et al. 1998. Phosphodiesterase 3 inhibitors suppress oocyte maturation and consequent pregnancy without affecting ovulation and cyclicity in rodents. J. Clin. Invest. 102:532-537.

28. Schultz, R.M., Montgomery, R.R., and Belanoff, J.R. 1983. Regulation of mouse oocyte meiotic maturation: implication of a decrease in oocyte cAMP and protein dephosphorylation in commitment to resume meiosis. Dev. Biol. 97:264-273.

29. Aberdam, E., Hanski, E., and Dekel, N. 1987. Maintenance of meiotic arrest by the invasive adenylate cyclase of Bordetella pertussis. Biol. Reprod. 36:530-535.

30. Maller, J.L. 2001. The elusive progesterone receptor in Xenopus oocytes. Proc. Natl. Acad. Sci. U. S. A. 98:8-10.

31. Sadler, S.E., and Maller, J.L. 1989. A similar pool of cyclic AMP phosphodiesterase in Xenopus oocytes is stimulated by insulin, insulin-like growth factor 1 and (Val 12, Th 59) Ha-ras protein. J. Biol. Chem. 264:856-861.

32. Andersen, C.B., et al. 2003. Protein kinase B/Akt is essential for insulin- but not progesterone-stimulated resumption of meiosis in Xenopus oocytes. Biochem. J. 369:227-238.

33. Choi, Y.-H., et al. 2001. Identification of a novel isoform of the cyclic-nucleotide phosphodiesterase PDE3A expressed in vascular smooth muscle myocytes. Biochem. J. 353:41-50.
34. Wechsler, J., et al. 2002. Isoforms of cyclic nucleotide phosphodiesterase PDE3A in cardiac myocytes. J. Biol. Chem. 277:38072-38078.

35. Kincaid, R.L., and Manganiello, V.C. 1988. Assay of cyclic nucleotide phosphodiesterase using radiolabeled and fluorescent substrates. Methods Enzymol. 159:457-470.

36. Jin, S.-L., Richard, F.J., Kuo, W.P., D’Ercole, A.J., and Conti, M. 1999. Impaired growth and fertility of cAMP-specific phosphodiesterase PDE4D-deficient mice. Proc. Natl. Acad. Sci. U. S. A. 96:11998-12003.

37. Conti, M., et al. 2003. Cyclic AMP-specific PDE4 phosphodiesterases as critical components of cyclic AMP signalling. J. Biol. Chem. 278:5493-5496.

38. Houslay, M., and Adams, D.R. 2003. PDE4 cAMP Phosphodiesterases: modular enzymes that orchestrate signaling cross-talk, desensitization, and compartmentalization. Biochem. J. 370:1-18.

39 Jin, S.-L., and Conti, M. 2002. Induction of cyclic nucleotide phosphodiesterase PDE4B is essential for LPS-activated TNF $\alpha$ response. Proc. Natl. Acad. Sci.U.S. A. 99:7628-7633.

40. Hansen, G., Jin, S.-L., Umetsu, D.T., and Conti, M. 2000. Absence of muscarinic cholinergic airway responses in mice deficient in the cyclic nucleotide phosphodiesterase PDE4D. Proc. Natl. Acad. Sci. U. S. A. 97:6751-6756.

41. Robichaud, A., et al. 2002. Deletion of phosphodiesterase $4 \mathrm{D}$ in mice shortens $\alpha 2$-adrenoreceptor-mediated anesthesia, a behavioral correlate of emesis. J. Clin. Invest. 110:1045-1052. doi:10.1172/ JCI200215506.

42. Josefberg, L.B., and Dekel, N. 2002. Translational and post-translational modifications in meiosis of the mammalian oocyte. Mol. Cell. Endocrinol. 187:161-171.

43. Lazar, S., Galiana, D., and Dekel, N. 2002. cAMPdependent PKA negatively regulates polyadenylation of c-mos mRNA in rat oocytes. Mol. Endocrinol. 16:331-341.

44. Brown, R.L., Ord, T., Moss, S.B., and Williams, C.J. 2002. A-Kinase Anchor Proteins as potential regulators of protein kinase A. function in oocytes. Biol. Reprod. 67:981-987.

45. Kovo, M., et al. 2002. Expression and modification of PKA and AKAPs during meiosis in rat oocytes. Mol. Cell. Endocrinol. 192:105-113.

46. Rueh, M.L., et al. 2003. Targeting of protein kinase A by muscle A kinase-anchoring protein (mAKAP) regulates phosphorylation and function of the skeletal muscle ryanodine receptor. J. Biol. Chem. 278:24831-24836.

47. Perry, S.J., et al. 2002. Targeting of cyclic AMP degradation to beta 2 -adrenergic receptors by betaarrestins. Science. 278:834-836.

48. Schmitt, A., and Nebreda, A.R. 2002. Inhibitition of Xenopus oocyte maturation by catalytically inactive protein kinase A. Proc. Natl. Acad. Sci. U. S. A. 99:4361-4366.

49. Svoboda, P., Stein, P., Hayashi, H., and Schultz, R.M. 2000. Selective reduction of dormant maternal mRNAs in mouse oocytes by RNA interference development. Development. 127:4147-4158.

50. Beavo, J.A., Conti M., and Heaslip, R.J. 1994. Multiple cyclic nucleotide phosphodiesterases. Mol. Pharmacol. 46:399-405. 